Document downloaded from:

http://hdl.handle.net/10251/43177

This paper must be cited as:

Serrano Cruz, JR.; Tormos Martínez, BV.; Gargar, KL.; Bouffaud, F. (2013). Study of the Effects on Turbocharger Performance Generated by the Presence of Foreign Objects at the Compressor Intake. Experimental Techniques. 37(2):30-40. doi:10.1111/j.17471567.2011.00795.x.

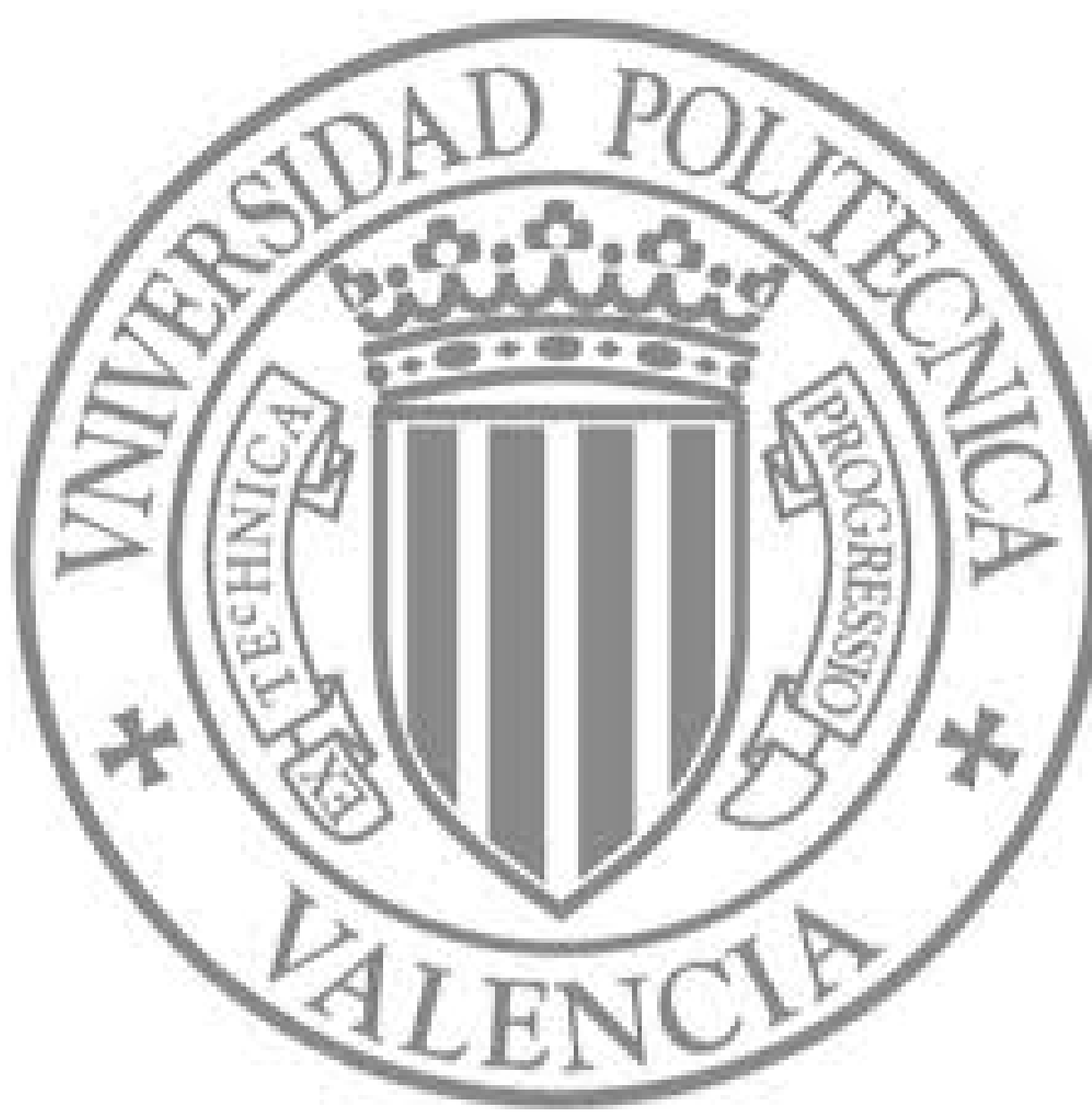

The final publication is available at

http://dx.doi.org/10.1111/j.1747-1567.2011.00795.x

Copyright Society for Experimental Mechanics (SEM) 


\title{
Study of the effects on Turbocharger performance generated by the presence of foreign objects at the compressor intake
}

\author{
J R Serrano ${ }^{\mathrm{a}}$, B Tormos ${ }^{\mathrm{a}}$, K L Gargar ${ }^{\mathrm{a}}$ and F Bouffaud ${ }^{\mathrm{b}}$
}

Address:

${ }^{\mathrm{a}} \mathrm{CMT}$ - Motores Térmicos.

Universidad Politécnica de Valencia.

Camino de Vera s/n, 46022 Valencia, Spain

E-mail: jrserran@mot.upv.es, betormos@mot.upv.es, kgagar@mot.upv.es

Telephone: +(34) 963879 657. Fax: +(34) 963877659

${ }^{*}$ Corresponding author

${ }^{\mathrm{b}}$ Renault, France

E-mail: francois.bouffaud@renault.com

Telephone: +(33) 176875542

\begin{abstract}
The study performed on this work consists of evaluating the consequences of the introduction of various foreign objects at the compressor inlet of a turbocharger. The most plausible objects were selected. A specific test bench was set up in order to perform the experiment and measure the compression ratio and compressor efficiency evolution. Measurements were performed before (healthy compressor) and after the object introduction (damaged compressor). Results obtained indicate that losses in performance can be very important, but also that the compressor can swallow hard objects without visible damage. Therefore the experiments were filmed with a high speed camera. Visual information has helped to better understand the phenomenon, to explain the measurements and it has been taken into account in order to perform final diagnosis. As expected, the harder the object is and the longer it hits compressor wheel before being swallowed, the most severe is the damage. Nevertheless, softer material can reach abnormal performance but in randomly manner and such incipient damage can be detected easily in high air flow rates than in lower.
\end{abstract}

\section{Keywords}

Automotive turbochargers, failure evaluation, efficiency turbocharger 


\section{Introduction}

Downsizing is a common trend in gasoline and diesel engines which consists in reducing engine displacement in order to reduce fuel consumption, and improving efficiency to keep performance and reduce emissions. Turbochargers are required to do so. Almost compulsory on Diesel engines, they are becoming more and more associated to gasoline engines as well. On cars and trucks, a turbocharger consists of a centrifugal radial compressor driven by a centripetal radial turbine, linked together by a rotor shaft. Due to its good balance between mass flow capacity and size ${ }^{1}$, the centrifugal compressor is mainly used. Theses turbochargers can run at maximum speed about $250 \mathrm{krpm}$ and must be extremely well balanced ${ }^{2}$. The turbine should not be too heavy to guaranty a low response time but strong enough to support exhaust gas high temperature and stresses. At the compressor side, as Galindo said ${ }^{3}$, one should be capable to attain high pressure ratios with low mass flow rates to improve the engine low end torque but the compressor shall be large enough to blow the maximum engine air flow rate.

As turbochargers are running at very high speed and temperature, many types of mechanical failures may occur, ${ }^{4,5,6}$. Additionally, turbochargers failures are inherently expensive and have a devastating effect on engine performance, thus a better knowledge on failures origin, propagation and final effects is required.

The intake of foreign material into the compressor or turbine wheels; high exhaust temperatures; and lubrication related problems are the most generally recurring reasons for turbocharger failure. This work is a part of a more ambitious project performed in order to assess origin and consequences of typical failures that may appear in turbochargers. Lubrication related problems such as: oil supply failure, oil pressure and viscosity variations, oil contamination, etc.; slight contacts between wheels and housings, wheels excessive unbalanced, etc. will be studied as well in this project. However, for this paper, we firstly focus on the effects on performance generated by foreign objects ingestion at the compressor intake. This ingestion of foreign objects can be derived from faulty engine maintenance or normal engine operation.

The main purpose of this work is to evaluate what will be occur when different types of objects, some likely to appear at the compressor intake, some less, hit the compressor wheel. Furthermore, in order to obtain this evaluation, a novel experimental methodology has been developed to obtain the results presented. This new methodology will also contribute to obtain a deeper knowledge in future works in this project.

These types of failures are not well reported in literature. The generated damages are usually obvious when disassembling the turbocharger, but here we assessed the consequences on turbocharger performance and consequently in engine performance. Two kinds of measured variables had been traditionally selected to do so:

- Vibrations (using a spectral analysis). 
- Thermodynamics parameters (turbocharger efficiency and compression ratio)

Using thermodynamic parameters, a straight forward evaluation of turbocharger performance can be made, but it is assumed a priori that in early failure stages would be very difficult to detect. This is the reason why additional vibration spectral analysis is done by some authors ${ }^{7,8}$. This way, slight deviations from the "normal behavior" may be detected improving the damage analysis sensitivity.

However, this paper deals with the results obtained by diagnosis trusting just in the thermodynamics parameters and in order to obtain a corroboration and better knowledge of the failure process. A big effort has been made in order to develop a novelty experimental procedure as well as an uncommon visualization device has been set up to observe and record the whole crash sequence that provide images not available in the literature.

\section{Experimental facilities.}

\subsection{Turbocharger test bench.}

For the characterization of a typical automotive turbocharger, the test bench has to supply the turbine with a necessary airflow similar to the flow of the exhaust gases of an internal combustion engine. An oil free screw compressor with a maximum flow capacity of $164 \mathrm{~L} / \mathrm{min}$ at a maximum discharging pressure of $0.35 \mathrm{MPa}$ (gauge), provides the mass flow necessary to the system. In order to simulate the hot exhaust gases, the airflow of the screw compressor also has to be heated by five electric resistances in order to reach $500^{\circ} \mathrm{C}$ at the turbine inlet. To warrant that flow through the heaters is balanced, manual valves are installed on inlet ports of each heater.

The amount of mass flow at the turbine inlet is controlled by changing the screw compressor speed, which is handled with a PID control. Since screw compressors do not permit operation at speeds lower than its minimum design point an electronically controlled discharge valve is placed in a derivation line between the screw compressor and the heaters, this gives the possibility to reduce the amount of flow at the turbine inlet by discharging some mass flow to surrounding. The amount of energy sent to the turbine is controlled with screw compressor speed and power of heaters. Air mass flow is cooled downstream of the turbine in order to allow mass flow measurement by commercial hot wire type flow meters. A serial installation of three flow meters allows a statistical treatment of the values, to control nonsystematic errors and to reduce the systematic ones. All flow meters on installation have been previously calibrated with a pattern. Figure 1 is a schematic representation of the continuous air flow test bench.

At the compressor side, upstream of the compressor, the flow goes through an air filter followed by three commercial hot wire type flow meters. At the compressor outlet, an electronically driven backpressure valve helps to modify compression ratio and mass flow by changing line losses as necessary. An oil filter ends the line in order to prevent oil leakages to the atmosphere where the air is discharged. 
An independent lubrication system delivers oil at an adjustable pressure in order to test different sizes of turbochargers. Optional heater and cooler allow adjusting the temperature at the inlet lube port of the turbocharger. Temperature, pressure and flow sensors on lube ports help to complete the energy balance and to control conditions for the correct operation of the unit.

Temperature and pressure sensors are installed on inlet and outlet pipes of the compressor and turbine. Sensor locations are made according to SAE J1826 standards ${ }^{9}$. Table 1 shows representative information about measurement range and accuracy of the sensors. More information about the turbocharger test bench here used can be found in ${ }^{10}$ and ${ }^{11}$.

The turbocharger test bench is equipped with a robust data acquisition system which stores the information from all sensors at the different measurement points. At the same time, the acquisition system also allows the monitoring and control of main variables to accomplish the requested tests.

In order to visualize the compressor blade movement when introducing the foreign object, a high speed Photron camera with light intensity has been used. The camera has a 10 bit CMOS sensor $(17 \mu \mathrm{m} / \mathrm{pixel})$ and for our study it was chosen to record at 15,000 frames per second and an exposure time of 1/40,000 s with a resolution of $256 \times 256$ pixels. The objective used is a SIGMA HF with 24-70 mm focal length. Specific software allows us to control completely the camera settings from the control room as speed, resolution, gain, etc. In order to improve the image recording, due to low light level at the compressor wheel a fiberglass pipe was designed and manufactured to increase the light. Furthermore, a spotlight of $1000 \mathrm{~W}$ was installed at the bottom of the fiberglass pipe in order to improve image quality as it can be seen in figure 2. A crystal window was located at the beginning of the pipe to protect the camera from objects that may come back after hitting the compressor wheel.

In order to carry on a vibration analysis and detect incipient damages that may not be evaluated trough the thermodynamics measurements, an accelerometer and a data acquisition system had been added to the bench. The accelerometer, Brüel \& Kjaer type 4384 (SN:1909599), was axially mounted on the compressor side of the turbocharger. Accelerometer is $200 \mathrm{~g}$ in weight and its sensitivity is 3pC/g in the range of 1 to $16.6 \mathrm{kHz}$. The signal from the sensor was transferred to a conditioning amplifier and then recorded at a sampling frequency of $50 \mathrm{kHz}$ using a data acquisition system. As previously mentioned, the vibration analysis is not presented in this paper. Although there are other options to measure turbocharger speed ${ }^{12}$, the accelerometer signal has been used to assess the turbocharger speed for this case. The location of the accelerometer can be observed on the figure 3.

\subsection{Type and size of objects.}


As on an engine the compressor inlet is protected by the air filter, foreign objects have to be introduced through a specific intake line. Five types of objects have been used in this experiment corresponding to those most plausible cases of compressor damage:

- $\quad$ Paper (thin slice of $\varnothing 30 \mathrm{~mm}$ ): as the air filters are made of paper, a piece of paper may break away from the air filter.

- $\quad$ Plastic washer $(\varnothing 10 \mathrm{~mm}$ and $1 \mathrm{~mm}$ thick): as intake manifolds are made of plastic material, a piece may break away downstream the air filter

- $\quad$ M6 Nut: of the type used to fit the air filter case.

Those two simulate parts that may accidentally fall into the air filter box when disassembled for maintenance.

- $\quad$ Ice slice (5x15x50mm) and ice sphere $(\varnothing 10 \mathrm{~mm})$ : wet air and blow-by gas in the intake line can condensate and sometimes freeze when ambient temperature goes down enough, forming ice.

An image of the different objects used in this study can be observed on figure 4.

\subsection{Testing Procedures.}

The introduction of the objects mentioned before has been done from two different distances from the wheel, 30 and $300 \mathrm{~mm}$, in order to evaluate possible effects of the inertia when the objects hit the wheel. For similar reasons, two different turbocharger speeds, 50 and $150 \mathrm{krpm}$, had been tested. Since all the tests had been repeated twice in each specific condition and for the five foreign objects, 40 different experiments had been conducted, and thus 40 turbochargers tested. To be able to compare the results of each test, a rigorous testing procedure has been defined. It is describe below:

a) A characterization test, to obtain performance and vibration reference level of each new turbocharger, was done.

- It consists first in assessing one of the speed lines of the compressor map, measuring compression ratio and efficiency for eight different air mass flows. The 150,000 rpm speed line has been chosen. The speed has been controlled during the experiment using the accelerometer mentioned before. To draw the speed line and adjust the eight different corrected air mass flow values required (from 0.032 to $0.117 \mathrm{~kg} / \mathrm{s}$ ), the counter pressure valve at the compressor side was set to a given position. A PID controlled the gas mass flow at turbine side in order to get the targeted speed.

- Afterward, a vibration measurement was done, first in steady state conditions at 150,000 rpm, and then in transient conditions at 7,500 rpm per second from 50,000 rpm to 150,000 rpm. 
All these characterization tests represented the standard reference level of the good condition of each turbocharger to be compared to after the object introduction.

b) The foreign object was then introduced at the compressor inlet. A high speed video was recorded.

c) After swallowing the object, a check out test of the damaged turbocharger was performed using the characterization method described above.

Before switching to a new turbo, a complete check out of the compressor intake line was done in order to guaranty that no air leakages may affect the results of the measurements. The check out test was made using an ultrasonic leakage detector (AccuTrack VPE).

\subsection{Object introduction system}

For security reasons, a specific object introduction system was designed (figure 5). This system is composed of two valves and an intermediate chamber: a manual valve through which the object is introduced to the intermediate chamber and closed after that and a pneumatic valve, controlled from the test room control area, to let the object fall in the intake line of the compressor when on demand.

Figure 6 represents a general view of the testing facility; the turbocharger is located in the centre.

\subsection{Turbocharger data and test matrix.}

Only one model of turbocharger had been used in this analysis. Its main characteristics are presented on Table 2.

Table 3 presents the test matrix for this study taking into account the three considered variables: type of foreign object, turbocharger speed when introduced, and distance from which the object is introduced.

\section{Results}

Next section presents the results obtained for the different tests performed.

\subsection{Characterization tests.}

As it has been said, in the characterization tests, it was calculated compressor efficiency and compression ratio from measured variables ( $\mathrm{SAE}^{9}$ and $\mathrm{CIMAC}^{13}$ standards have been followed in the calculation) for each new turbocharger at different corrected air mass flows. Figure 7 present typical results for characterization test on a specific turbocharger. In order to check the repetitiveness of the tests and that no measurement problem appeared, each new turbocharger data was added to a general graph. The deviation obtained for each measurement was computed. In one case, for example, this led to detect an abnormal behaviour of the fifth turbocharger measured. Investigations revealed leakages at the compressor inlet duct. Taking into account this situation, a leakage detection inspection was developed and incorporated to the testing procedures for the subsequent experiments. 
When no problem occurs, the dispersion over measurements in a group of different turbochargers tested is low (figures 8 and 9) and, as may be observed on the efficiency measurements, the dispersion increases with the air mass flow.

Additionally, a statistical analysis was performed on the compression ratio and the compressor efficiency. The normality of the statistics has been verified as illustrated below on figure 10 and figure 11.

Table 4 summarizes the characterization statistics values. The testing configuration used to introduce the foreign objects $30 \mathrm{~mm}$ far from the compressor wheel has an impact on the global efficiency as a consequence of the disturbance in air inlet flow generating a negative effect that reduces the efficiency as attested by the measurements.

\subsection{Foreign objects introduction.}

The high speed camera helped to understand the effects of the foreign objects ingestion. Some snap shots are reproduced on figures 12 (nut) and 13 (ice cube). The repetitive hits of the nut over the compressor wheel lead to a progressive severe damage of the blades. The inspection of the compressor disassembled confirmed the video recorded. On figure 13, the snap shots witness the destruction of the ice cube, rather than the milling of the compressor wheel. The final condition of the compressor wheel does not show any appreciable damage.

\subsection{Check out test}

In most of the tests performed, the object was swallowed by the compressor. The measurement of the compressor efficiency and compression ratio could then be performed without any disassembling.

The nuts tests were stopped before swallowing the nuts because the wheels were already clearly damaged. It's impossible and pointless to assess how long the test should last to swallow the nut. It's just obvious that the longer the nuts mills the wheel, and the faster the wheel speeds, the more severe is the damage as shown on figure 14.

Individual check-out results had been compared the corresponding characterization tests. The nuts led to the most severe damages. Figure 15 present the results obtained for the turbocharger T13. An important deviation from characterization may be observed. It was necessary to disassemble the compressor housing to remove the nut before measuring the thermodynamics parameters again.

For a selected air mass flow (here $0.068 \mathrm{~kg} / \mathrm{s}$ corresponding to the maximum efficiency), the graphs presented on figure 16 summarize the measurements of all the compressor performances after swallowing foreign objects. Dot lines represent the characterization performances (mean \pm 2 sigma), so it is easy to identify which tests that led to significant damages.

As can be observed on graphs presented on figure 16, the nut tests show performances significantly out of the statistical boundaries defined by the normal conditions 
As can be observed on graphs presented on figure 17, obtained for a higher value of air mass flow (0.09 kg/s), not only nuts presents abnormal behavior with T10 (plastic) clearly out of statistical boundaries and tests for T5 (paper), T9 (plastic) and T21 (ice cube) presenting values on the edge of limits. This situation can lead to conclude that up to medium mass flow $(0.07 \mathrm{~kg} / \mathrm{s}$ in our case) the wheel has to be seriously damaged to detect any effect on the compression performances. Thus only hard foreign objects like nuts significantly impact the performances. Looking at higher flow rates (above $0.09 \mathrm{~kg} / \mathrm{s}$ for this case) allows detecting smaller damages.

\section{Recuperation of lost energy}

In order to make a valuation of the effect of damage generated on a real application in energy terms, an additional study was made. The idea was to evaluate compressor losses after swallowing the object and measure the extra energy that a damaged turbocharger needs in order to reach the original performances (when healthy).

A test was done using a turbo damaged by a nut. The energy required to recover a given air mass flow and compression ratio corresponding to the original maximum efficiency point was computed as shown on figure 18.

The damaged turbocharger had to run about 30krpm faster and requested about 1800 Watts additional to reach the same compression characteristics.

Calculation of the power spent by the compressor:

$$
\begin{aligned}
& \dot{W}_{\text {comp }}=m \cdot c_{p} \cdot\left(T_{\text {comp_outlet }}-T_{\text {comp_inlet }}\right) \\
& \frac{\dot{W}_{\text {damaged_comp }}}{\dot{W}_{\text {healthy_comp }}}=\frac{5867 \text { Watt }}{4118 \text { Watt }}=1.42
\end{aligned}
$$

Where:

$$
\begin{array}{ll}
\dot{W}_{\text {comp }} & =\text { Compressor Power }(\text { Watt }) \\
\dot{m} & =\text { Mass flow }(\mathrm{kg} / \mathrm{s}) \\
c_{p} & =\text { Average specific heat at constant pressure }(\mathrm{J} / \mathrm{kgK}) \\
T & =\text { Temperature }(\mathrm{K})
\end{array}
$$

The efficiency dropped down by $23 \%$, and about $40 \%$ of additional work was required to recover the original compression characteristics.

\section{Conclusions}

It could be supposed "a priori" that parameters used in order to evaluate the turbochargers behavior, taking into account that all of them are equals (same manufacturer and type) will follow normal distribution behavior. Parameters used have been: efficiency and compression ratio and have presented such " $a$ priori” behavior. It has been also presented a novel experimental technique that allows combining the same experiment visualization with high speed camera, foreign objects introduction and compressor performance measurement in a reliable way. 
With respect to tests conclusions, nuts are the only foreign object that generated on the compressor wheel damage big enough to compromise further use of the turbocharger and as a consequence turbocharged engine performance. Nut damage was clearly observed on the measurements of thermodynamics parameters, in such a way that turbochargers damaged cannot even recover the original maximum compression ratio without significantly overspeeding (around 14\% in the example test). This leads to a huge energy consumption increase (about 40\%). If the experiments had been carried on until the nuts were swallowed by the compressor, the compressor wheel would have been totally destroyed and performances impossible to recover.

Using videos recorded on each test, it has been observed that almost all the objects generate limited damages. It has been tested that is easier to detect incipient failures in points where high air flow mass rates are involved, and in these cases could be observed that softer material (such as paper or plastic) can lead to abnormal performance although in a random manner. One explanation is that as long as they are fragile, few hits cannot significantly damage the wheel, and the objects are disintegrated and swallowed quite rapidly. This situation is different with harder objects like nuts, where the residence time or test time lead to proportionally severe damages. It is also worth highlighting that if the objects are just soft but not fragile (i.e. paper in the study or eventually rubber piece) and the compressor kicks do not disintegrate them, in such a way that must be swallowed in only one piece by the compressor wheel, the object can deform wheel spinning while swallowing, generating incipient damages not observed in maximum efficiency performance but present in visualization and at maximum mass flow conditions.

\section{Aknowledgements}

The authors wish to thank to Spanish Grant TRA2007-65433/TAIR from Ministerio de Educación y Ciencia. D.G. Investigación for supporting this work. 


\section{References}

1. Watson N. and Janota M. S. “Turbocharging the Internal Combustion Engine.” Macmillan, London, 1982.

2. Gjika K, Larue G. D., "Dynamic behaviour of rotor-bearing systems involving two oil films in series-application to high-speed turbochargers” IMechE Conference Transactions C602/021/2002. Seventh International Conference on Turbochargers and Turbocharging (2002).

3. Galindo J., Serrano J. R., Guardiola C. and Cervelló C. "Surge limit definition in a specific test bench for the characterization of automotive turbochargers,” Exp. Ther. Fluid Sci. 30:449-462 (2006).

4. Engels B. "Lifetime prediction for turbocharger compressor wheels-why use titanium?” IMechE Conference Transactions C602/037/2002. Seventh International Conference on Turbochargers and Turbocharging (2002).

5. Ahdad F., Soare M. A., "Prediction of duration of life of automotive components under thermomechanical fatigue" IMechE Conference Transactions C602/020/2002. Seventh International Conference on Turbochargers and Turbocharging (2002).

6. Osako K., Jinnai Y., et al. "Development of the High-Performance and High-Reliability VG Turbocharger for Automotive Applications” Mitsubishi Heavy Industries, Ltd. Technical Review Vol. 43 No. 3 (2006).

7. Holmes R., "Turbocharger vibration - a case study" IMechE Conference Transactions C692/031/2002. Seventh International Conference on Turbochargers and Turbocharging (2002).

8. Zhao X., He H., Xu S. "Influence of the Floating-Ring Bearing Parameters on Stability of Turbocharger Rotor-Bearing System” Proceedings of the Fourth International Symposium od Fluid Machinery and fluid Engineering. Pp 421-425. Springer ISBN 978-7-302-18788-2. (2008).

9. SAE J1826 1995 Turbocharger Gas Stand Test Code, Recommended Practice

10. Luján J. M., Bermudez V., Serrano J. R., and Cervelló C. "Test Bench for Turbocharger Groups Characterization," SAE Paper 2002-01-0163.

11. Serrano J. R., Guardiola C., Dolz V., Tiseira A. and Cervelló C. "Experimental Study of the Turbine Inlet Gas temperature influence on Turbocharger Performance,” SAE Paper 2007-01-1559.

12. Macián V., Luján J. M., Bermudez V. and Guardiola C. "Exhaust pressure pulsation observation from turbocharger instantaneous speed measurement,” Meas. Sci. Technol. 15:1185-1194 (2004).

13. The International Council on Combustion Engines (CIMAC). "Turbocharging Efficicencies Definitions and guidelines for measurements and calculation," 2007. 


\section{$\underline{\text { List of figure captions }}$}

Figure 1. Layout of the facility.

Figure 2. Setting up of the camera face to the compressor entrance (left) and location of the spotlight at the bottom of the fiberglass pipe (right).

Figure 3. Left: location of the piezo-electric accelerometer and right: example of frequency graph showing the turbocharger speed.

Figure 4. Picture of the objects and size used to hit the compressor wheel. From left to right: (a) paper, (b) plastic, (c) nuts, (d) ice cube and (e) ice sphere.

Figure 5. Left: manual valve for the introduction of the foreign objects and right: pneumatic valve controlled from the test room control area.

Figure 6. General view of the testing facility.

Figure 7. T15 compressor efficiency and compression ratio data from characterization.

Figure 8. Efficiency characterization measurements for different turbochargers.

Figure 9. Compression ratio characterization measurements for different turbochargers

Figure 10. Normal probability plot for Efficiency results of turbochargers on test performed from $300 \mathrm{~mm}$

Figure 11. Histogram plot for Compression ratio results of turbochargers on test performed from $30 \mathrm{~mm}$.

Figure 12. Sequence of frames during the nut introduction and final condition of the compressor wheel (turbocharger $\# 13)$.

Figure 13. Sequence of frames during the ice cube introduction.

Figure 14. Comparative damages after nut introduction with different testing time. Left: turbocharger \#29, tested at 50 krpm. Right: turbocharger \#13, tested at $150 \mathrm{krpm}$.

Figure 15. Results for compressor efficiency and compression ratio in a turbocharger damaged with nut.

Figure 16. Values obtained for compressor efficiency (left) and compression ratio (right) in the check out tests at 0.068 $\mathrm{kg} / \mathrm{s}$ air mass flow for the distance $30 \mathrm{~mm}$.

Figure 17. Values obtained for compressor efficiency (left) and compression ratio (right) in the check out tests for 0.09 $\mathrm{kg} / \mathrm{s}$ air mass flow for the distance of $30 \mathrm{~mm}$.

Figure 18. Comparative data obtained from the analysis for recuperation of lost energy. 


\section{TABLES}

Table 1. Characteristics of sensors employed in the test bench.

\begin{tabular}{c|c|c|c}
\hline Variable & Sensor type & Measuring Range & Error \\
\hline & & $0 \sim+5 \mathrm{bar}$ & $\pm 0.025 \mathrm{bar}$ \\
Pressure & Piezoresistive & $0 \sim-1 \mathrm{bar}^{\mathrm{a}}$ & $\pm 2.2^{\circ} \mathrm{C}$ \\
Temperature & Thermocouple (K type) & $-200 \sim+1200^{\circ} \mathrm{C}$ & $\pm 0.72 \mathrm{~kg} / \mathrm{h}$ \\
Flow & Hot wire & $0 \sim 720 \mathrm{~kg} / \mathrm{h}$ & \\
\hline
\end{tabular}

${ }^{\mathrm{a} O n l y}$ for compressor inlet 
Table 2. Main turbocharger characteristics.

\begin{tabular}{cccc}
\hline Turbine & Compressor & General & \\
\hline $\begin{array}{c}\text { Type: Fixed Geometry } \\
\text { Turbine }(\mathrm{FGT})\end{array}$ & Suction $\varnothing 37 \mathrm{~mm}$ & $\begin{array}{c}\text { Minimum oil pressure: } \\
\text { MPa at idling }\end{array}$ & 0.05 \\
\hline $\begin{array}{c}\text { Suction } \varnothing 28 \mathrm{~mm} \\
\text { Discharge } \varnothing 38 \mathrm{~mm}\end{array}$ & Discharge $\varnothing 36 \mathrm{~mm}$ & $\begin{array}{c}\text { Minimum oil pressure: } \\
\text { MPa at full load }\end{array}$ & 0.1 \\
\hline Wheel $\varnothing 35 \mathrm{~mm}$ & Wheel $\varnothing 41 \mathrm{~mm}$ & $\begin{array}{c}\text { Maximum rotor speed: } \\
\text { rpm }\end{array}$ & \\
\hline $\begin{array}{c}\text { Maximum temperature at } \\
\text { turbine inlet: } 760^{\circ} \mathrm{C}\end{array}$ & $\begin{array}{c}\text { Maximum recommended } \\
\text { temperature inlet } 60^{\circ} \mathrm{C}\end{array}$ & \\
\hline
\end{tabular}


Table 3. Test matrix.

\begin{tabular}{|c|c|c|c|}
\hline Turbocharger \# & Object & Speed (krpm) & Distance (mm) \\
\hline $\mathrm{T} 3$ & Paper & 50 & 30 \\
\hline $\mathrm{T} 4$ & “ & 50 & 30 \\
\hline $\mathrm{T} 5$ & “ & 150 & 30 \\
\hline T6 & “ & 150 & 30 \\
\hline T7 & Plastic & 50 & 30 \\
\hline T8 & “ & 50 & 30 \\
\hline T9 & “ & 150 & 30 \\
\hline $\mathrm{T} 10$ & “ & 150 & 30 \\
\hline T11 & Nut & 50 & 30 \\
\hline $\mathrm{T} 12$ & “ & 50 & 30 \\
\hline T13 & “ & 150 & 30 \\
\hline $\mathrm{T} 14$ & “ & 150 & 30 \\
\hline T15 & Ice Cube & 50 & 30 \\
\hline T16 & “ & 50 & 30 \\
\hline $\mathrm{T} 17$ & “ & 150 & 30 \\
\hline $\mathrm{T} 21$ & “ & 150 & 30 \\
\hline T18 & Ice Sphere & 50 & 30 \\
\hline T19 & “ & 50 & 30 \\
\hline T20 & “ & 150 & 30 \\
\hline $\mathrm{T} 23$ & “ & 150 & 30 \\
\hline T24 & Paper & 50 & 300 \\
\hline Т32 & “ & 50 & 300 \\
\hline $\mathrm{T} 25$ & “ & 150 & 300 \\
\hline Т33 & “ & 150 & 300 \\
\hline T26 & Plastic & 50 & 300 \\
\hline T34 & “ & 50 & 300 \\
\hline $\mathrm{T} 27$ & “ & 150 & 300 \\
\hline T35 & “ & 150 & 300 \\
\hline T28 & Nut & 50 & 300 \\
\hline $\mathrm{T} 42$ & “ & 50 & 300 \\
\hline T29 & “ & 150 & 300 \\
\hline T44 & “ & 150 & 300 \\
\hline T30 & Ice Cube & 50 & 300 \\
\hline $\mathrm{T} 40$ & “ & 50 & 300 \\
\hline T31 & “ & 150 & 300 \\
\hline T41 & “ & 150 & 300 \\
\hline T36 & Ice Sphere & 50 & 300 \\
\hline T38 & “ & 50 & 300 \\
\hline Т37 & “ & 150 & 300 \\
\hline Т39 & “ & 150 & 300 \\
\hline
\end{tabular}


Table 4. Main statistical results for characterization test (maximum efficiency point)

\begin{tabular}{cccc}
\hline & & Distance $30 \mathrm{~mm}$ & Distance $300 \mathrm{~mm}$. \\
\hline Efficiency & Average & $76.7 \%$ & $78.0 \%$ \\
& Standard deviation & 0.4 & 0.8 \\
& Confidence Interval & \pm 0.2 & \pm 0.4 \\
& Distribution fitting & Normal distribution & Normal distribution \\
\hline Compression ratio & Average & 1.65 & 1.66 \\
& Standard deviation & 0.02 & 0.01 \\
& Confidence Interval & \pm 0.0 & \pm 0.0 \\
& Distribution fitting & Normal distribution & Normal distribution \\
\hline
\end{tabular}




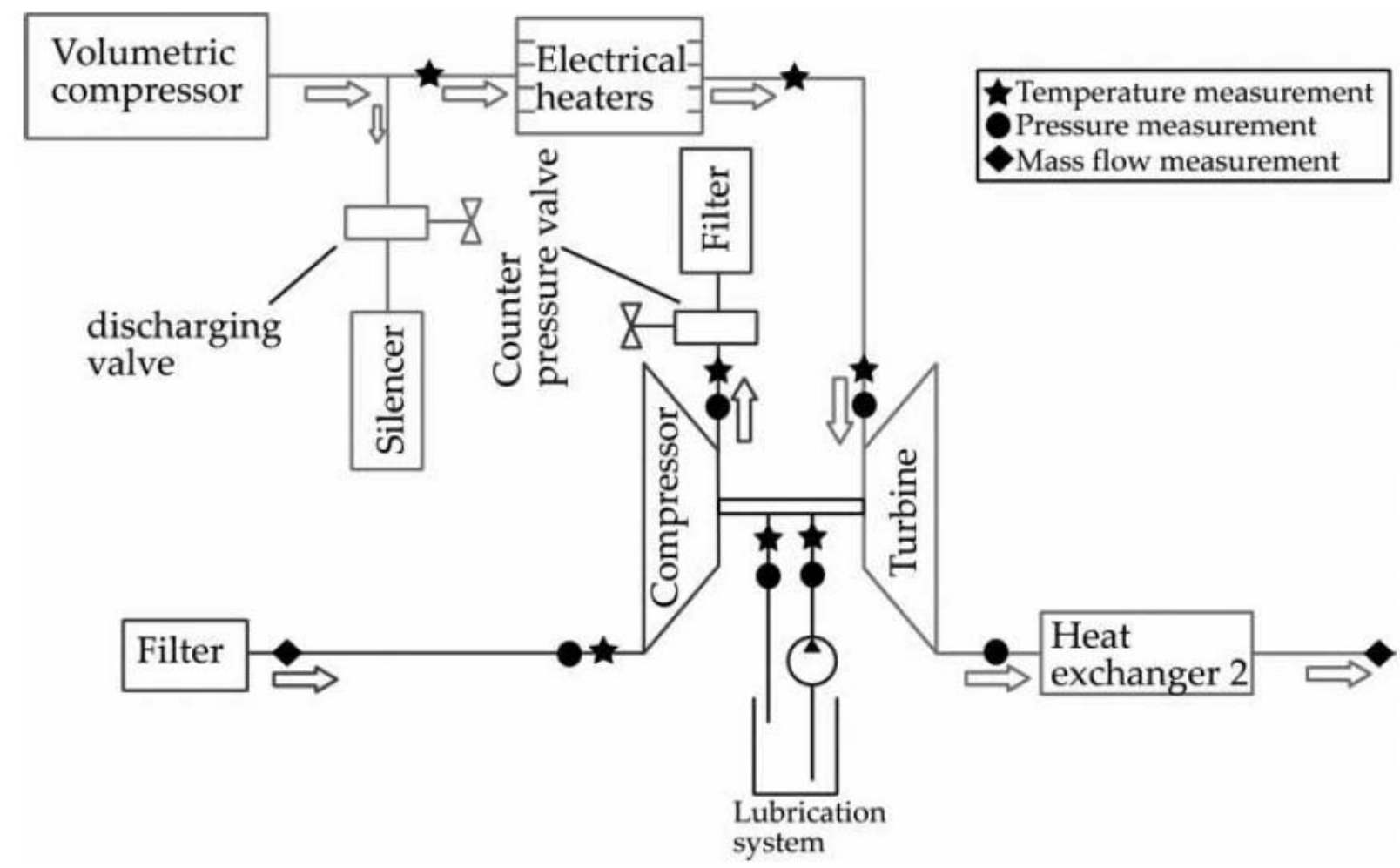

Figure 1
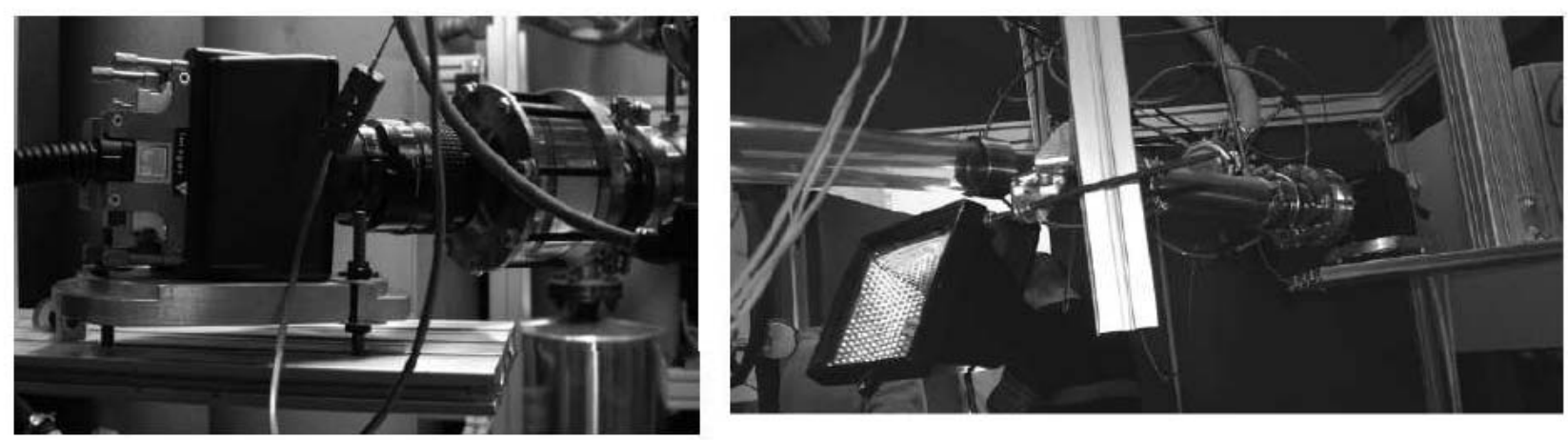

Figure 2 

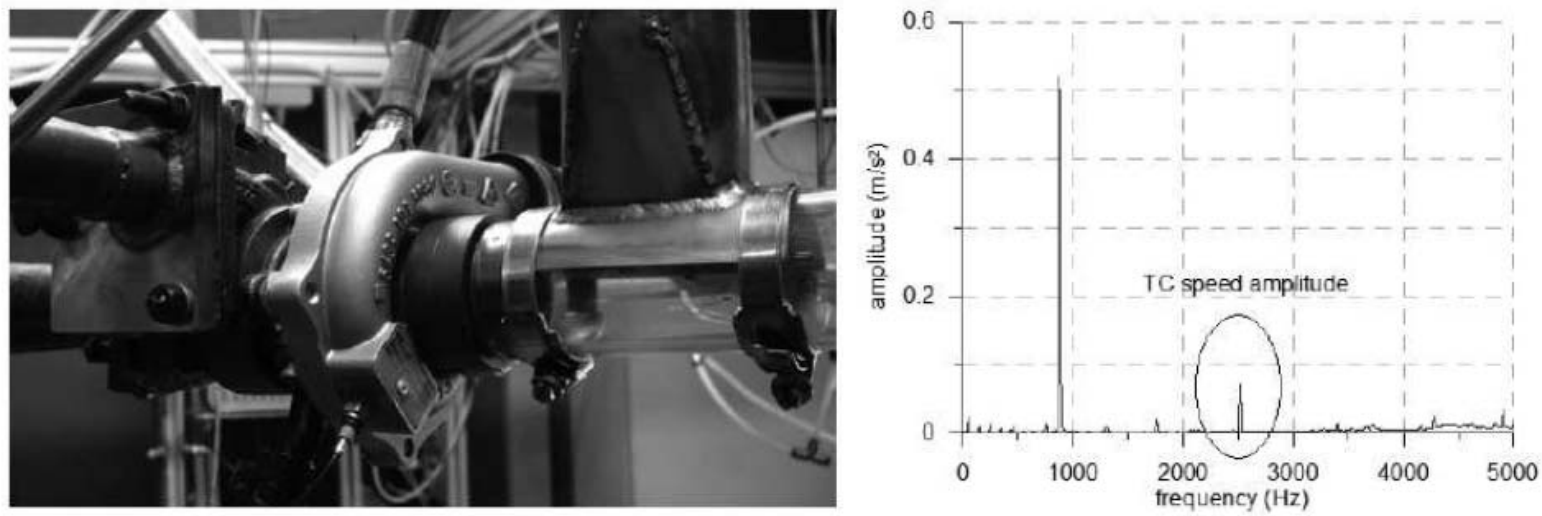

Figure 3
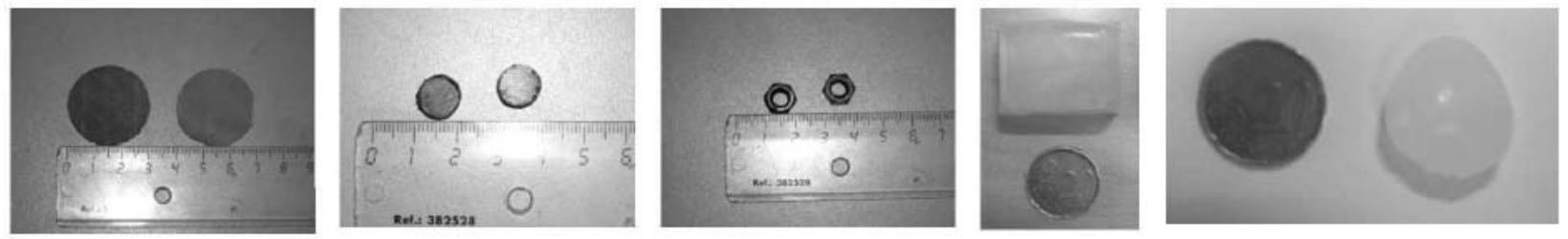

Figure 4
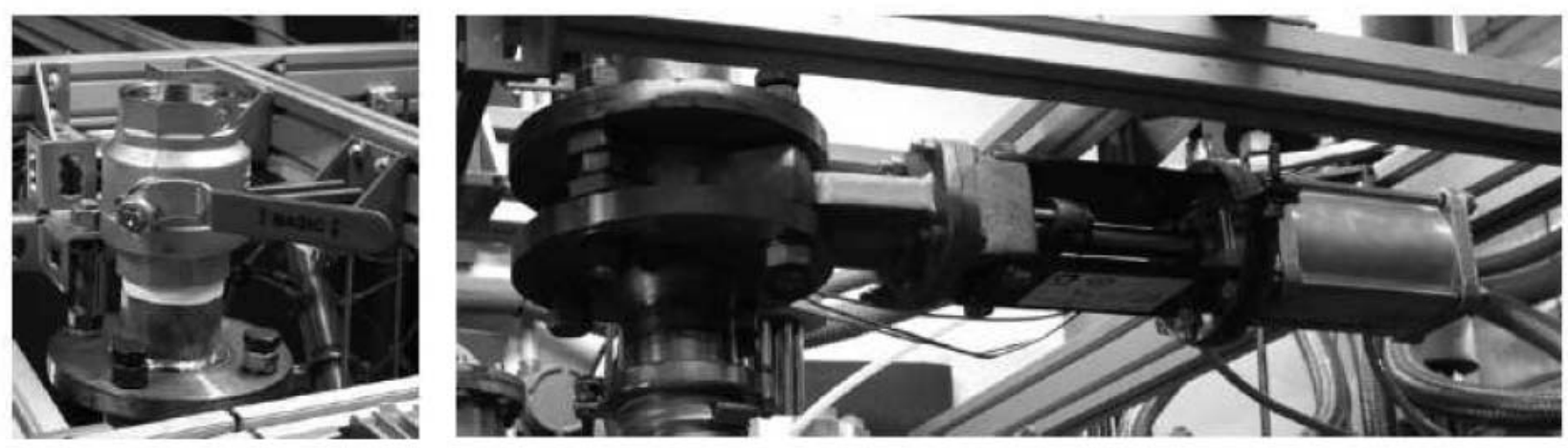

Fiqure 5 


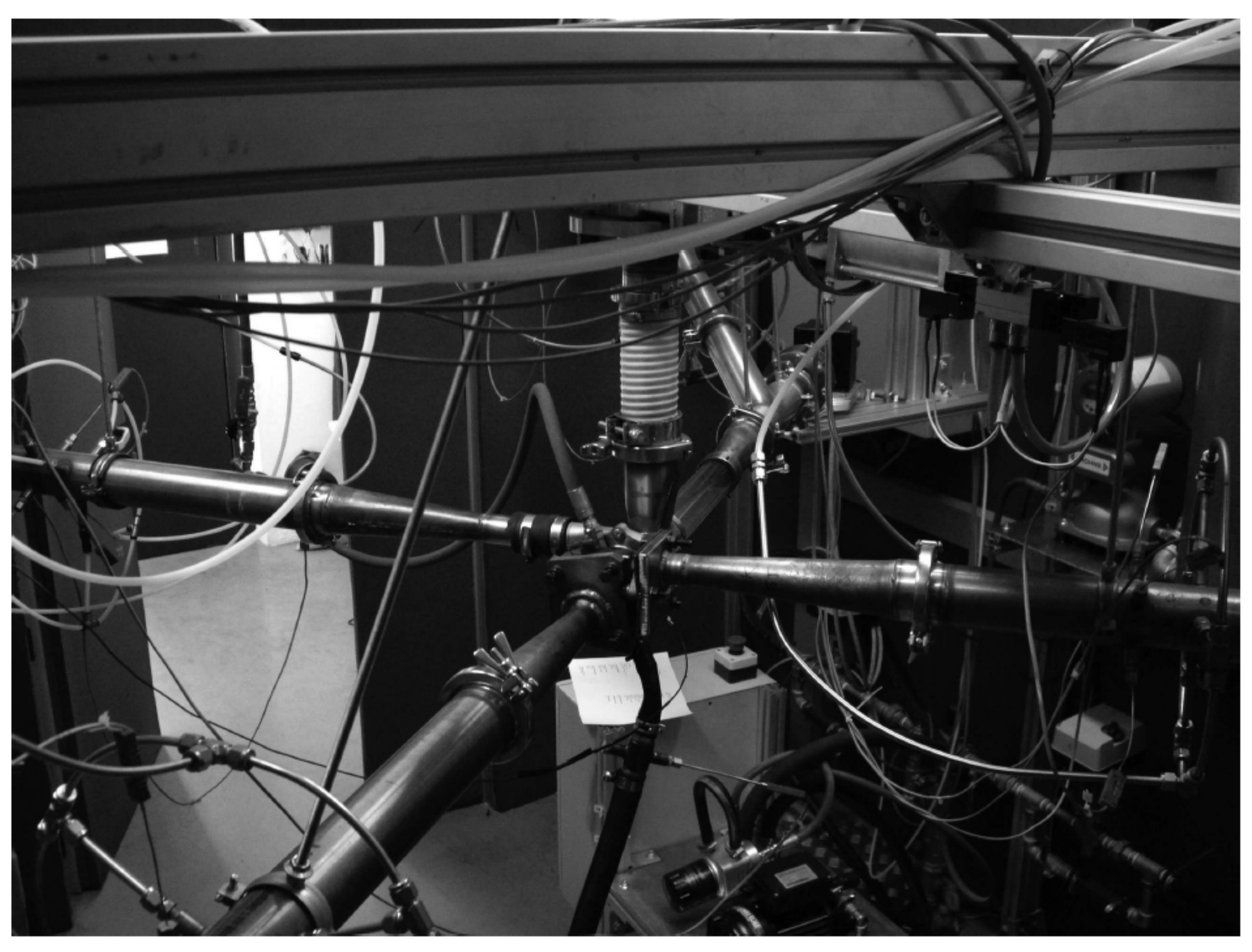

Fiqure 6 


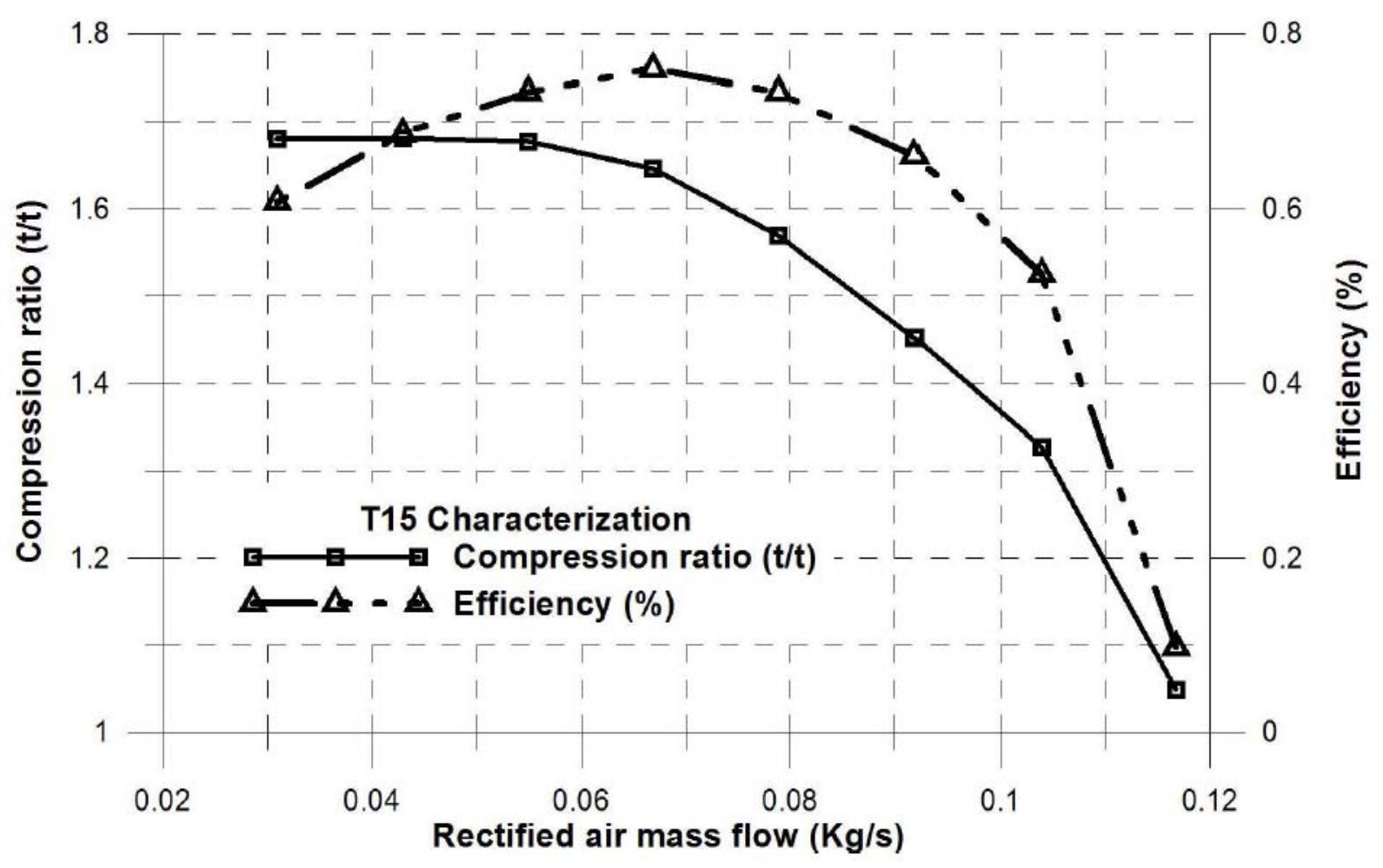

Figure 7 


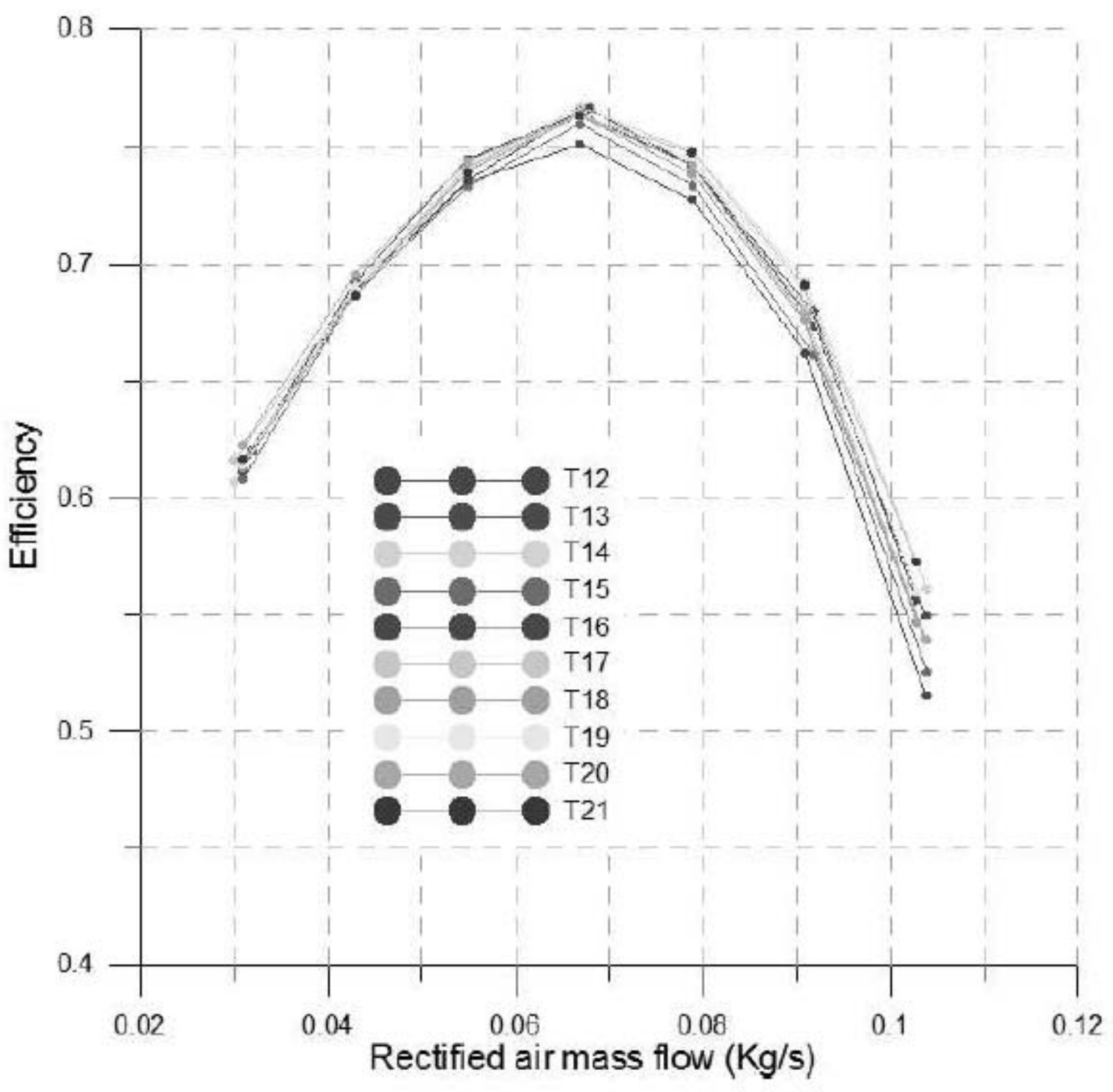

Fiqure 8 


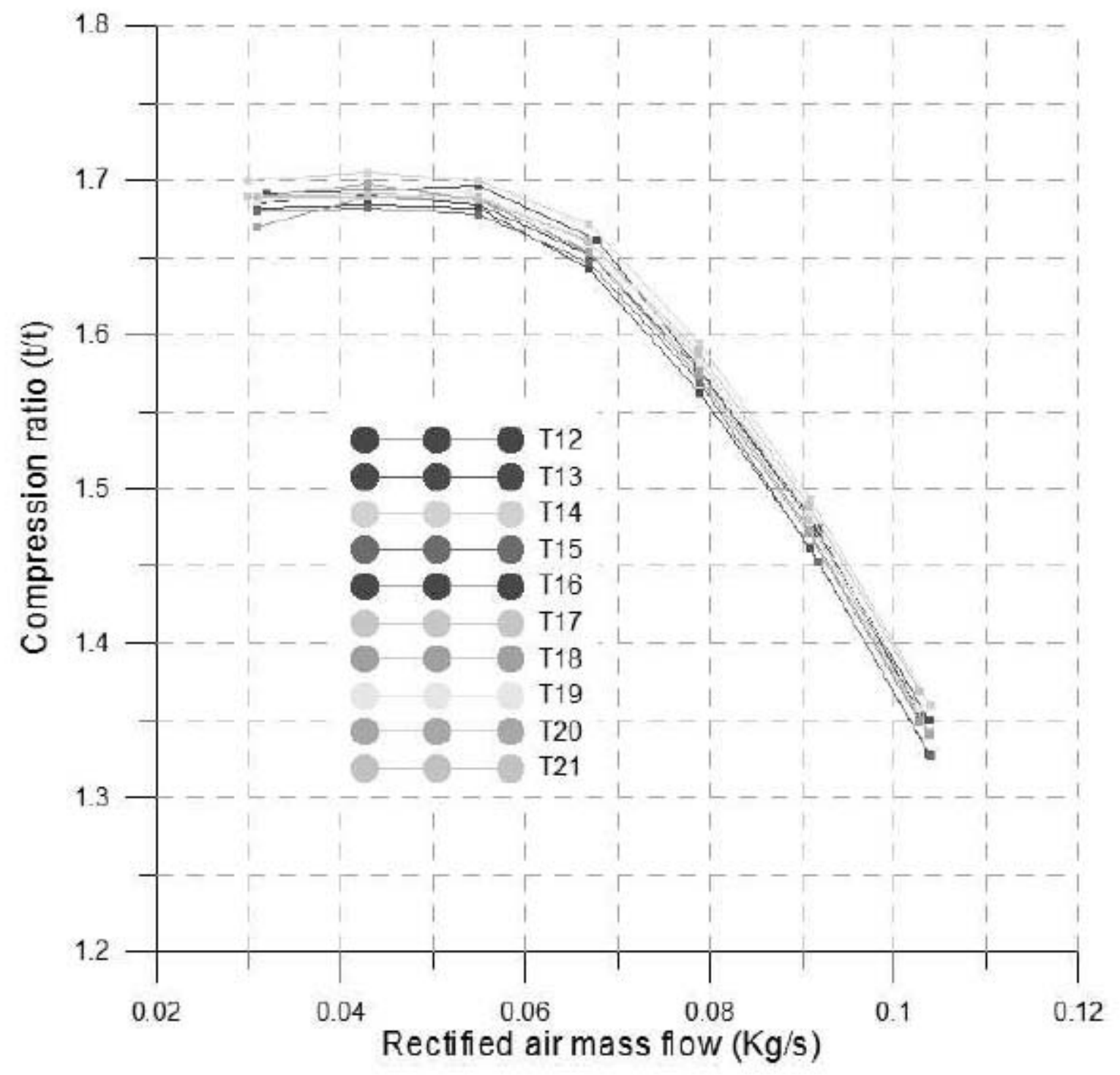

Figure 9 
Normal Probability Plot

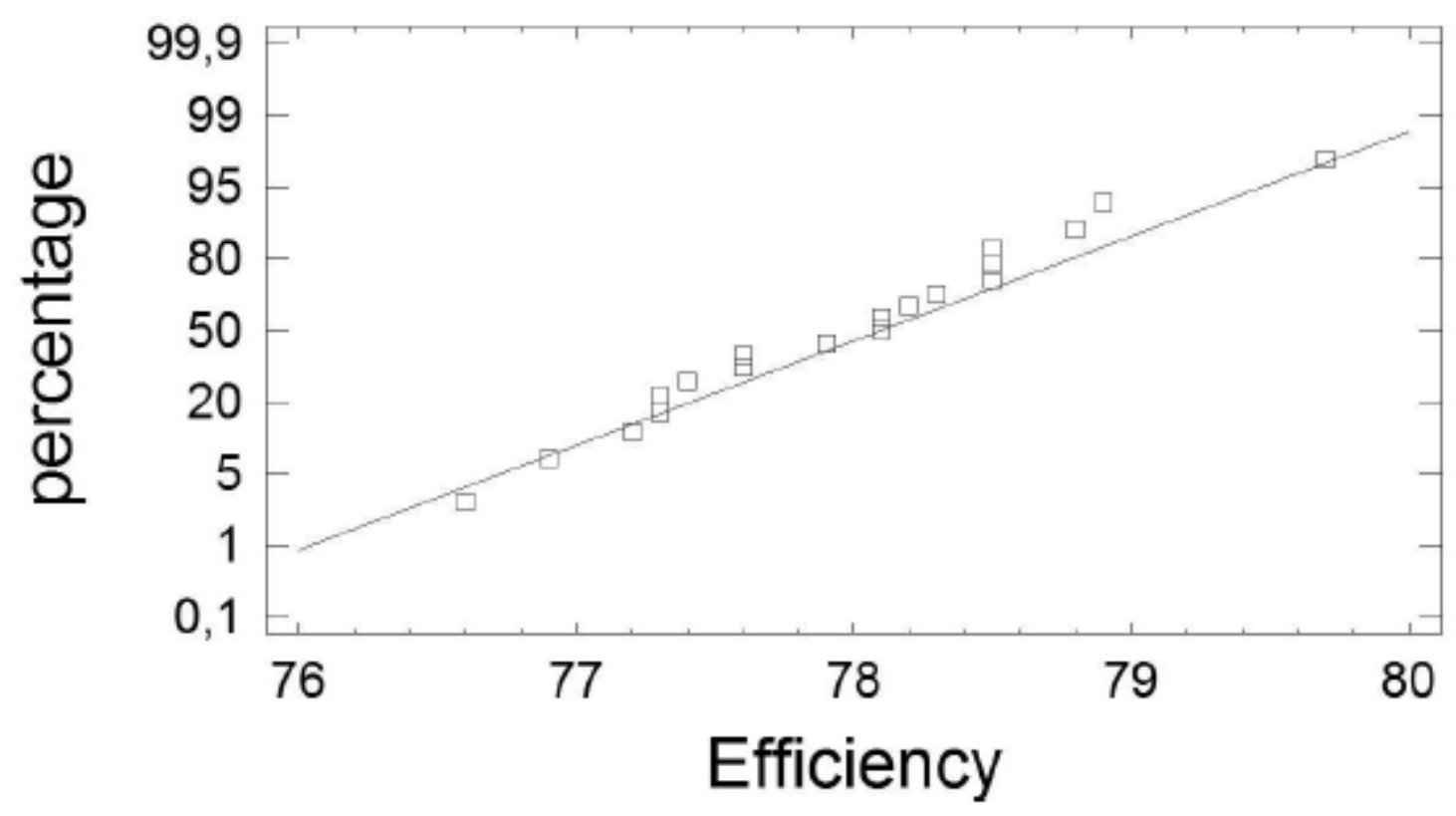

Figure 10

Histogram for Compression Ratio

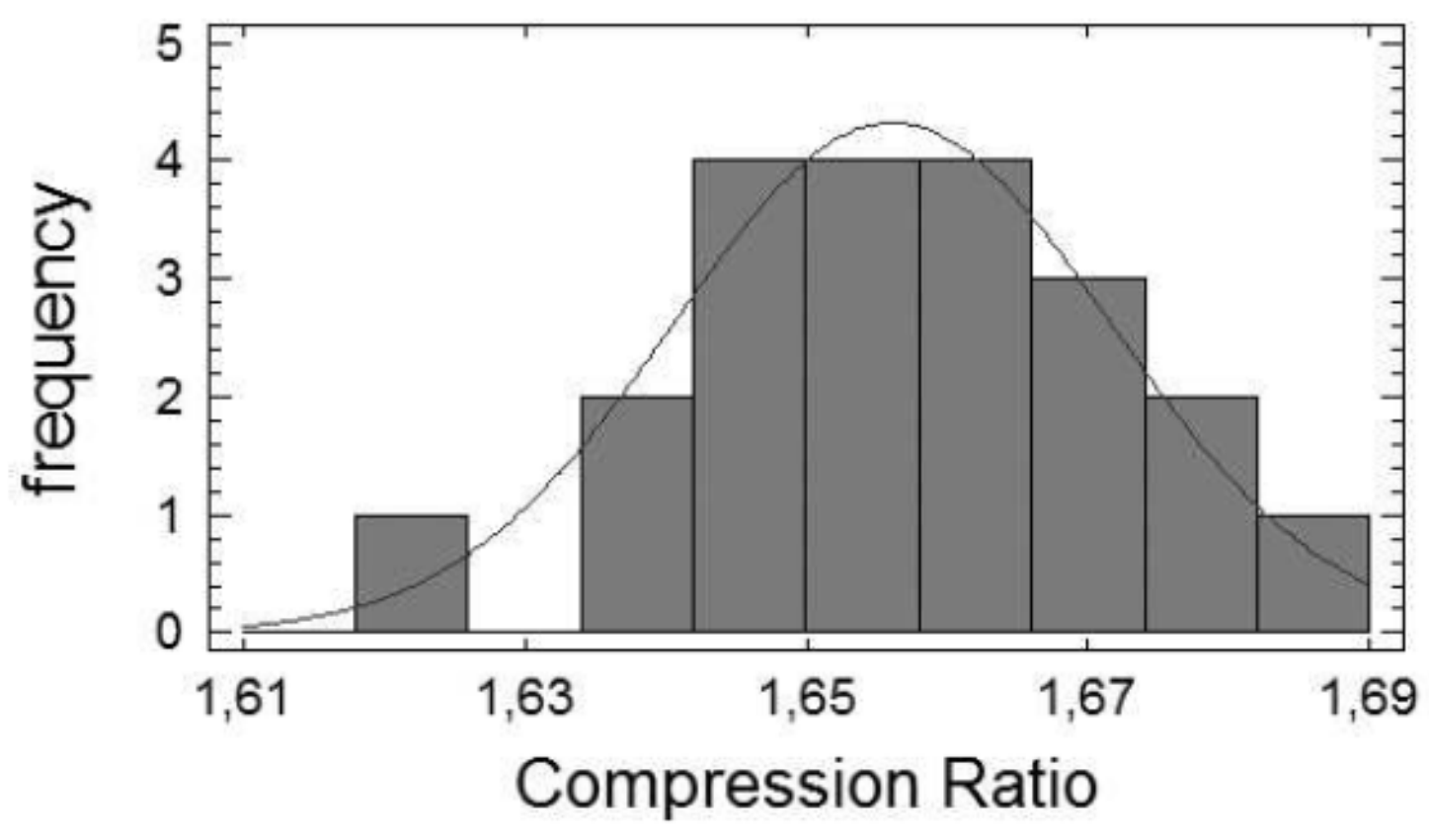

Figure 11 

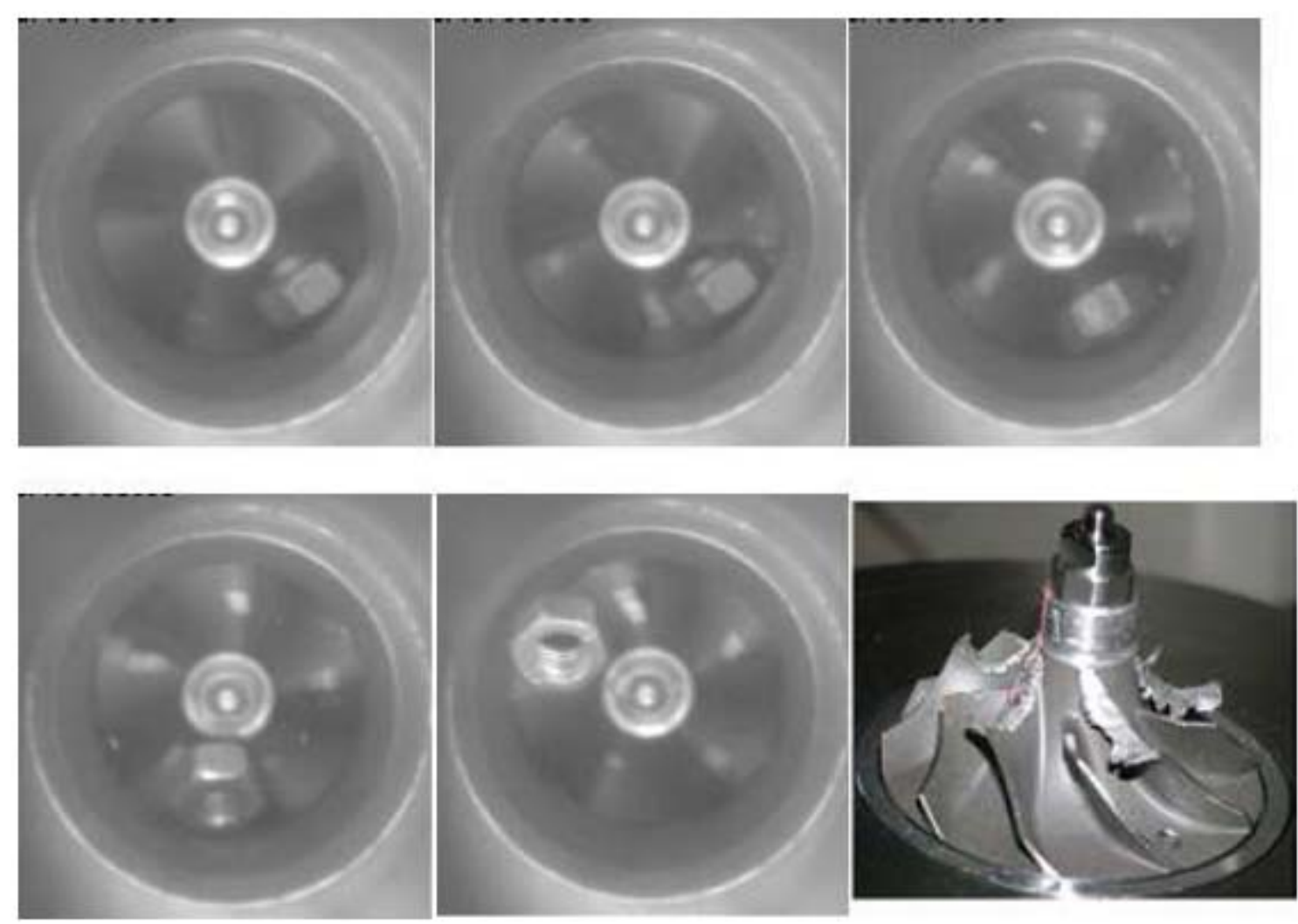

Fiqure 12

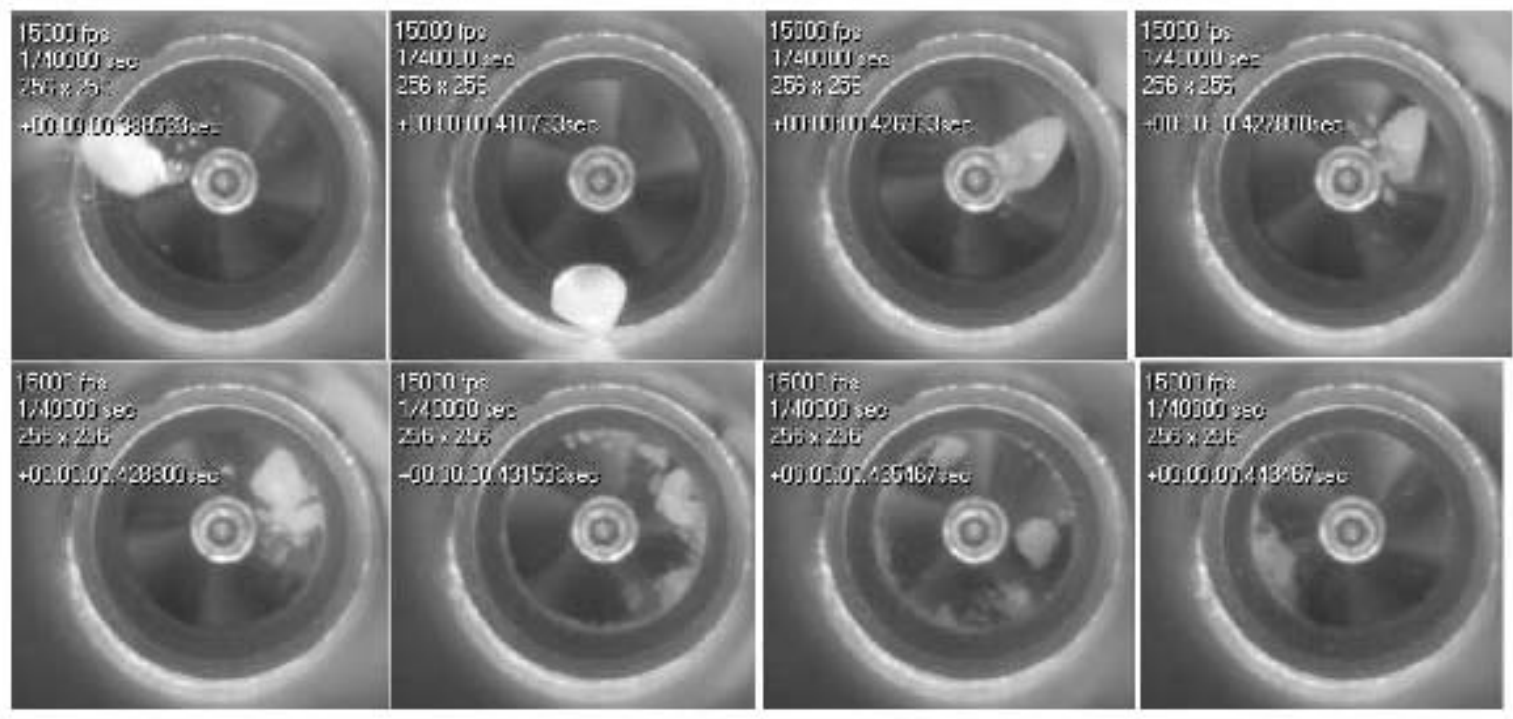

Figure 13 

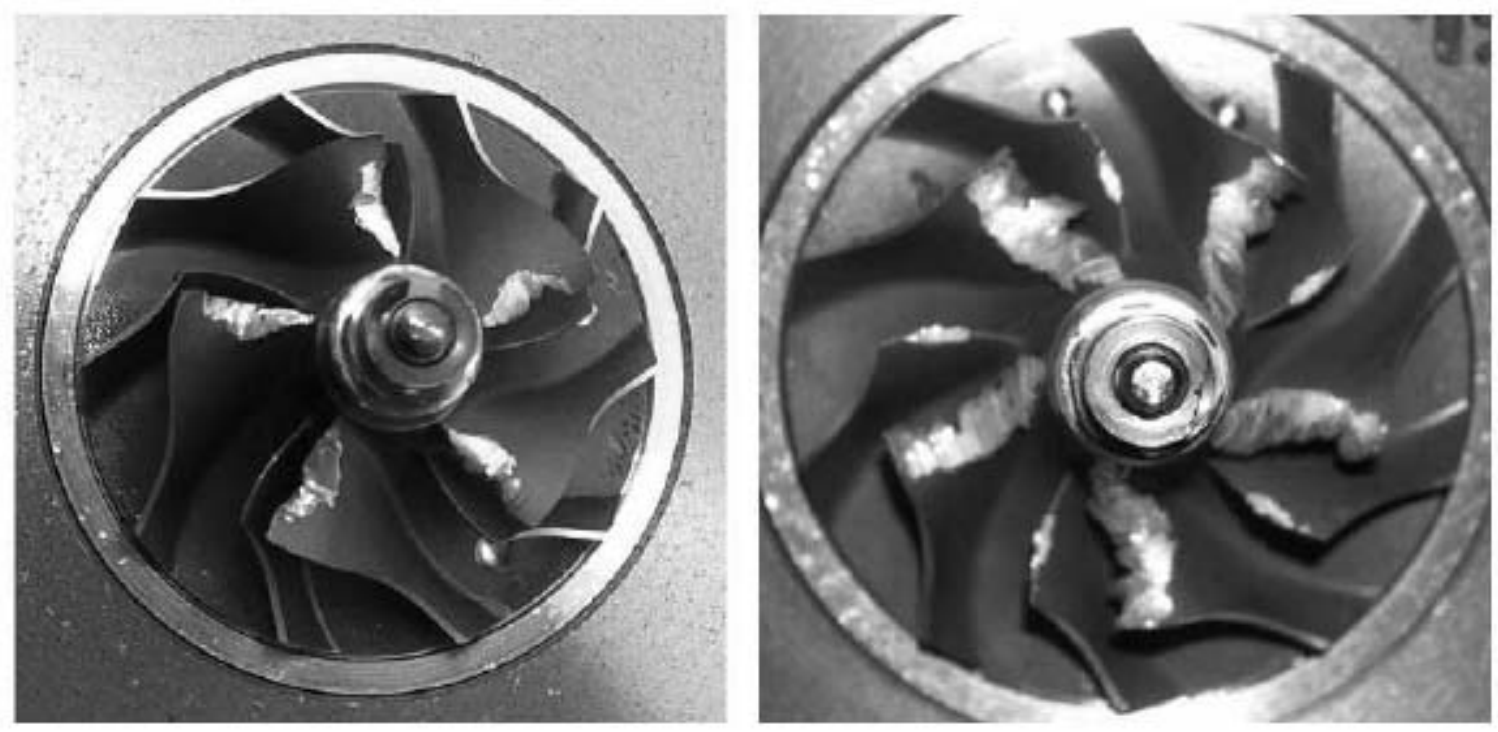

Figure 14

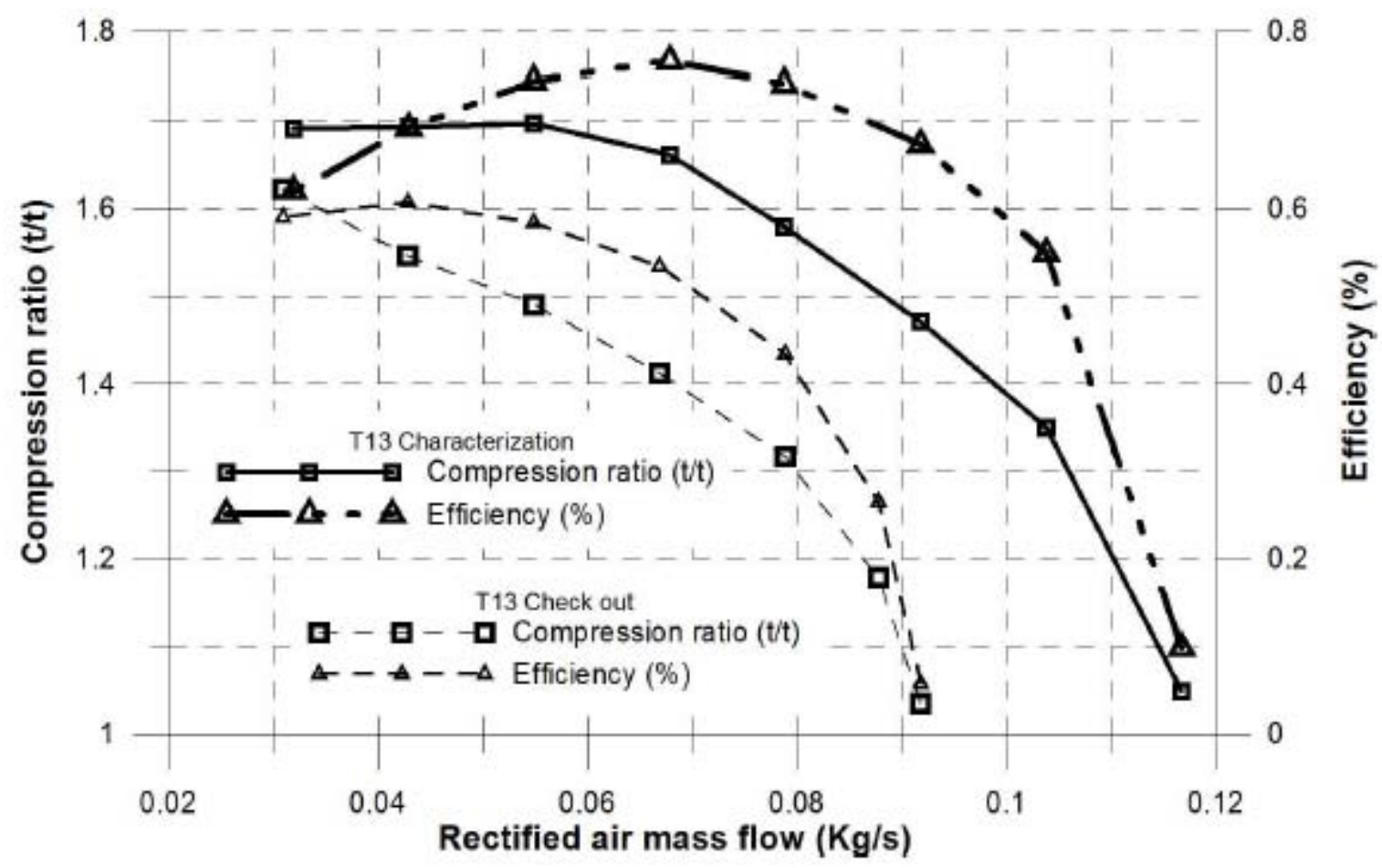

Fiqure 15 

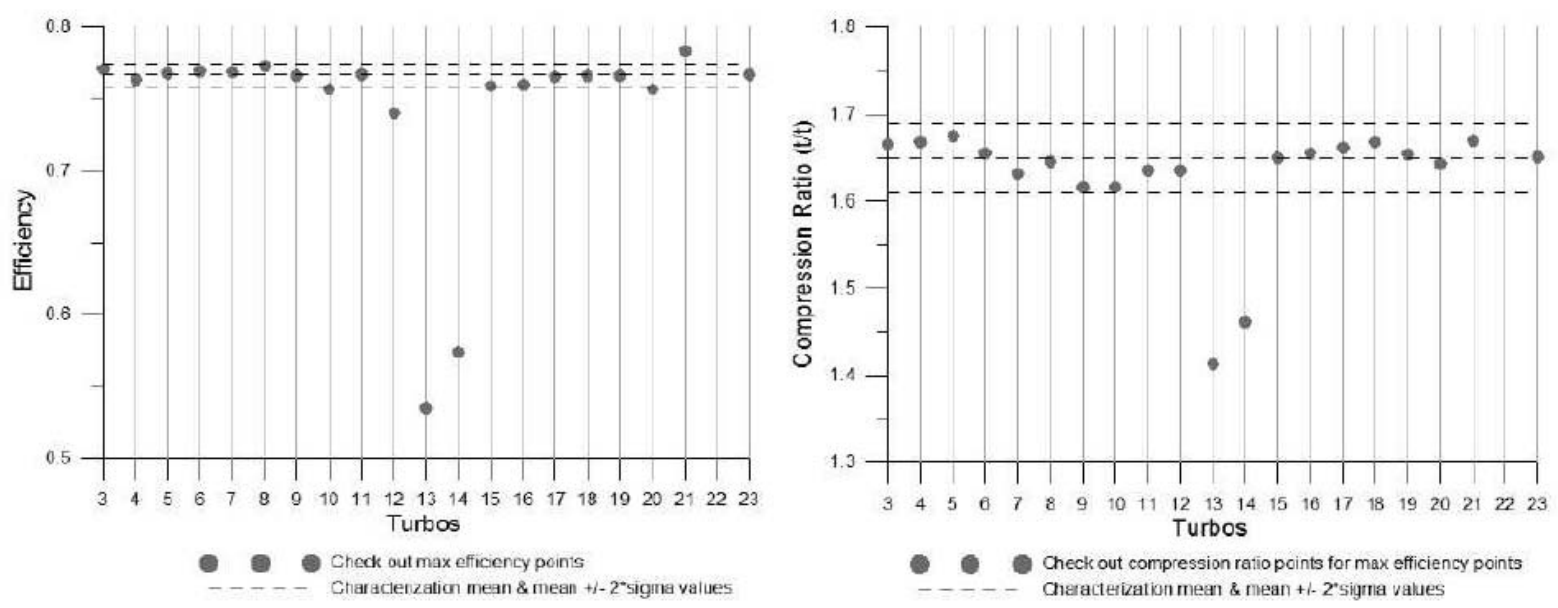

Figure 16
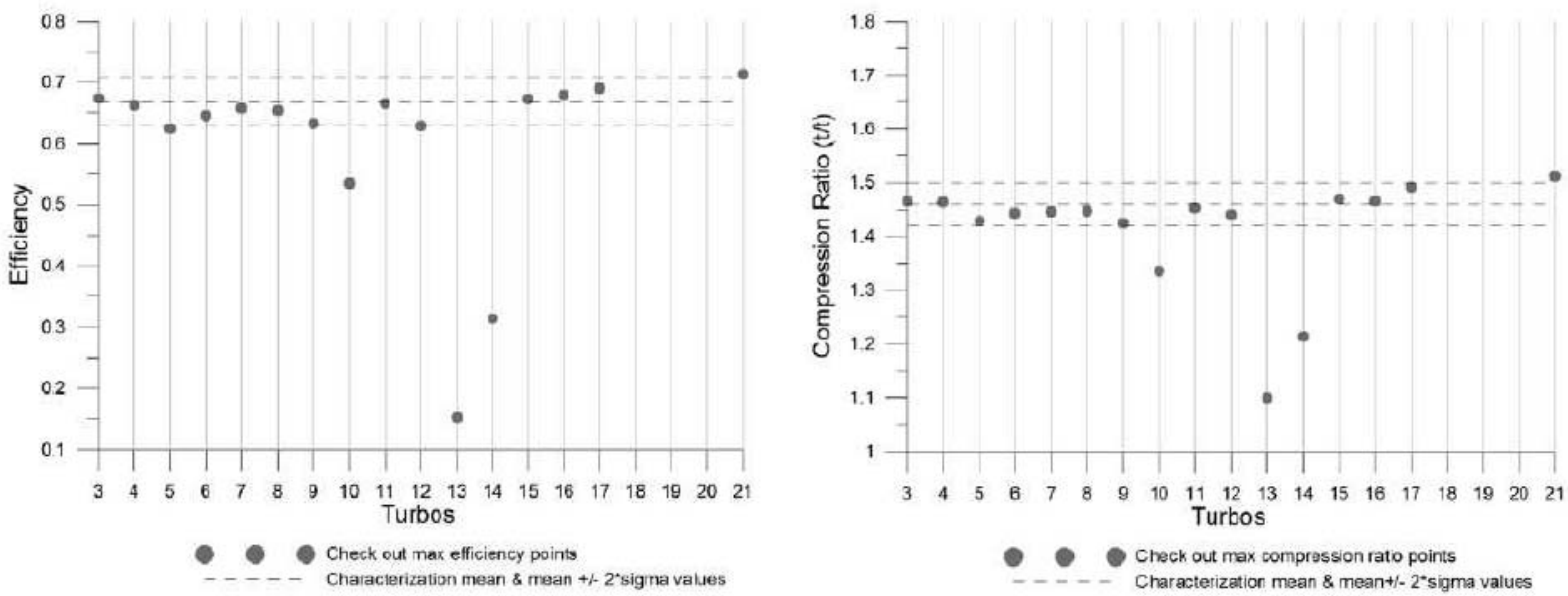

Figure 17
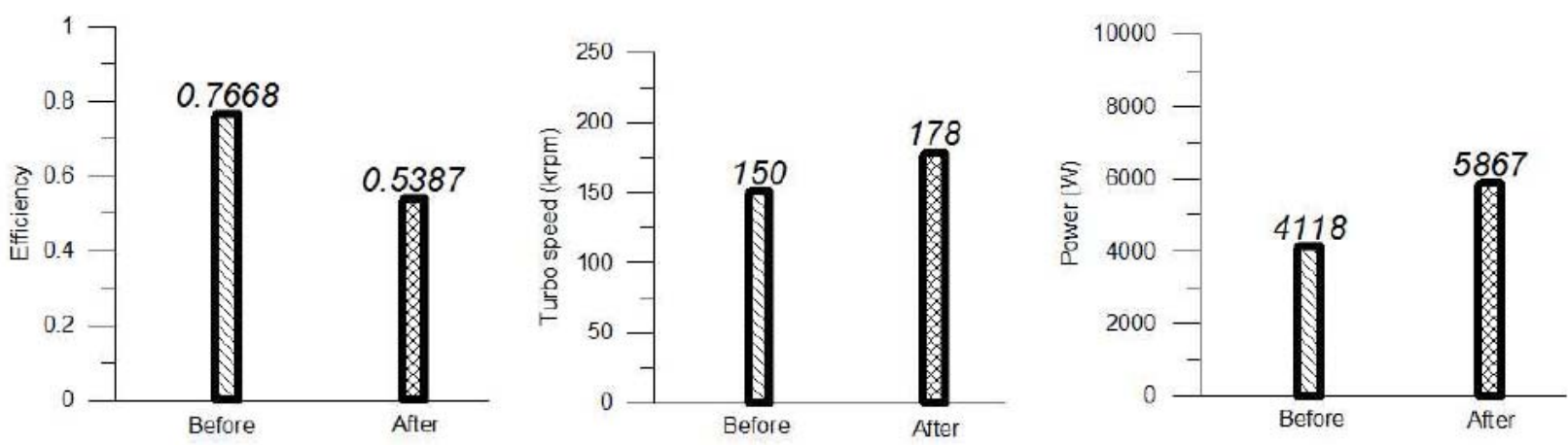

Figure 18 